www.nature.com/hr

\title{
REVIEW
}

\section{Dietary methyl-consuming compounds and metabolic syndrome}

\author{
Shi-Sheng Zhou ${ }^{1,2}$, Yi-Ming Zhou ${ }^{3}$, Da $\mathrm{Li}^{1}$ and Yong-Zhi Lun ${ }^{2}$
}

The metabolic syndrome, a major risk factor for type 2 diabetes and cardiovascular disease, is a cluster of metabolic abnormalities including obesity, insulin resistance, hypertension and dyslipidemia. Although systemic oxidative stress and aberrant methylation status are known to have important roles in the development of metabolic syndrome, how they occur remains unclear. The metabolism of methyl-consuming compounds generates reactive oxygen species and consumes labile methyl groups; therefore, a chronic increase in the levels of methyl-consuming compounds in the body can induce not only oxidative stress and subsequent tissue injury, but also methyl-group pool depletion and subsequent aberrant methylation status. In the past few decades, the intake amount of methyl-consuming compounds has substantially increased primarily due to pollution, food additives, niacin fortification and high meat consumption. Thus, increased methyl consumers might have a causal role in the development and prevalence of metabolic syndrome and its related diseases. Moreover, factors that decrease the elimination/ metabolism of methyl-consuming compounds and other xenobiotics (for example, sweat gland inactivity and decreased liver function) or increase the generation of endogenous methyl-consuming compounds (for example, mental stress-induced increase in catecholamine release) may accelerate the progression of metabolic syndrome. Based on current nutrition knowledge and the available evidence from epidemiological, ecological, clinical and laboratory studies on metabolic syndrome and its related diseases, this review outlines the relationship between methyl supply-consumption imbalance and metabolic syndrome, and proposes a novel mechanism for the pathogenesis and prevalence of metabolic syndrome and its related diseases. Hypertension Research (2011) 34, 1239-1245; doi:10.1038/hr.2011.133; published online 4 August 2011

Keywords: cardiovascular disease; diet; metabolic syndrome; methyl-consuming compounds; niacin

\section{INTRODUCTION}

The metabolic syndrome, a major risk factor for type 2 diabetes (T2D) and cardiovascular disease (CVD), is a cluster of metabolic abnormalities including obesity, insulin resistance, hypertension and dyslipidemia. ${ }^{1,2}$ In the past few decades, there has been an exponential increase in the prevalence of metabolic syndrome worldwide not only in adults but also in children and adolescents. For example, in the United States, the prevalence of obesity, a major component of metabolic syndrome, has doubled in the adult population ${ }^{3}$ and tripled in the adolescent population only in two decades (1980s and 1990s), ${ }^{4}$ while the prevalence of diabetes, the primary clinical outcome of metabolic syndrome, has also doubled during the past two decades (1988-2008) and still shows an increasing trend. ${ }^{5}$ To date, although the exact cause of metabolic syndrome remains unknown, it is known that diet may have a major role in the pathogenesis and prevalence of metabolic syndrome. ${ }^{6}$

Increasing evidence indicates that the pathogenic mechanism underlying metabolic syndrome and its clinical outcomes may involve oxidative stress, characterized by an increased production of reactive oxygen species (ROS), ${ }^{1}$ and aberrant methylation status, characterized by changes in the levels of plasma methyl donors ${ }^{7}$ and homocysteine $^{8-12}$ and altered DNA methylation (an epigenetic mechanism that alters gene expression). ${ }^{2}$ Recently, emerging evidence suggest that DNA methylation may be involved in the regulation of insulin gene expression in $\mathrm{T} 2 \mathrm{D}$ and the pathogenesis of insulin resistance. ${ }^{13-15}$ Therefore, understanding the origin of oxidative stress and aberrant methylation status is of both fundamental and practical importance in identifying the cause of metabolic syndrome.

Methyl consumers include a variety of compounds that are metabolized by methylation and are known to be involved in both the generation of ROS and aberrant methylation status of the body. Methyl consumers from dietary sources are usually toxic xenobiotics, such as pesticides, heavy metals, food additives and even clinical drugs. In the past few decades, there has been a significant increase in methyl consumers in dietary sources that is primarily due to pollution, food additives and food fortification. Therefore, the focus of this review was on the possible role of methyl consumers in the development of metabolic syndrome.

${ }^{1}$ Department of Physiology, Medical College, Dalian University, Dalian, China; ${ }^{2}$ Institute of Basic Medical Sciences, Medical College, Dalian University, Dalian, China and ${ }^{3}$ Section of Cell Signaling, Okazaki Institute for Integrative Bioscience, National Institute for Physiological Sciences, National Institutes of Natural Sciences, Okazaki, Japan Correspondence: Dr S-S Zhou, Department of Physiology, Medical College, Dalian University, No. 10 Xuefu Road, Dalian Economic and Technical Development Zone, Dalian 116622, China. 


\section{METHYL CONSUMERS AND THE METHIONINE- HOMOCYSTEINE CYCLE}

Biological methylation is ubiquitous and important in many cellular mechanisms including inactivation/elimination of small molecules and xenobiotics, stabilization of DNA and proteins, small molecule biosynthesis and cellular signaling. ${ }^{16}$ Methylation status reflects a balance between methyl supply from dietary methyl donors (primarily betaine, choline and methionine) and methyl consumption by a variety of endogenous and exogenous methyl consumers.

All biological methylation reactions in the body use $S$-adenosylmethionine (SAM), that is derived from the methionine-homocysteine cycle, as methyl donor. ${ }^{16}$ As shown in Figure 1, a substrate is converted to a methylated metabolite by its own methyltransferase, in which SAM, after donating its methyl group to the acceptor molecule, is converted to $S$-adenosylhomocysteine (SAH). The resulting SAH is rapidly hydrolyzed by adenosylhomocysteinase into homocysteine and adenosine. The methionine-homocysteine cycle is completed by the remethylation of homocysteine via either a folatedependent pathway catalyzed by vitamin $\mathrm{B}_{12}$-dependent methionine synthase, or a betaine-dependent pathway catalyzed by betainehomocysteine $S$-methyltransferase. Betaine is derived from either diet or the conversion of choline by choline oxidase. ${ }^{17}$ It has an important role in maintaining the methionine-homocysteine cycle, not only for its direct participation in the methylation of homocysteine to form methionine, but also for its metabolites that contribute to the formation of 5,10-methylenetetrahydrofolate, the precursor of 5-methyltetrahydrofolate. ${ }^{18,19}$

Because all of the methyl consumers from either endogenous or exogenous sources share the same pool of labile methyl donors, it is conceivable that an increase in any methyl consumer(s) may influence not only the methylation of other methyl consumers due to its increasing demand for labile methyl groups. Therefore, there seems to be no doubt that the level of methyl consumers is an important factor in determining the methylation profiles of the body, which has been largely ignored in the etiological study of metabolic syndrome and its related diseases.

\section{METHYL CONSUMERS AND HYPERHOMOCYSTEINEMIA}

Increased plasma concentration of homocysteine (that is, hyperhomocysteinemia) is frequently associated with T2D and CVD. ${ }^{8-12}$ Since both diseases are the primary clinical outcomes of metabolic syndrome, understanding of the cause of hyperhomocysteinemia may shed light on the etiology of metabolic syndrome. Plasma homocysteine levels are determined by three main factors: (1) the remethylation rate of homocysteine to methionine; (2) the conversion rate of homocysteine to cystathionine; and most importantly, (3) the amount of methylation of substrates.

One possible cause for the increasing prevalence of hyperhomocysteinemia and CVD may be folate deficiency, as evidence suggests that folate deficiency and methylenetetrahydrofolate reductase gene C667T polymorphism, a common genetic variation, may be involved in elevated fasting homocysteine. ${ }^{20,21}$ However, increasing evidence from clinical trials indicates that although folic acid and vitamin $B_{12}$ supplementation could reduce plasma homocysteine levels, they have no effect on T2D and cardiovascular events. ${ }^{22-25}$ This implies that the increased prevalence of CVD may not be a simple matter of folate deficiency. Moreover, excessive folic acid may lead to a waste of labile methyl-group donors. The underlying mechanism will be discussed in the later part of the review.

Another possible cause for the increasing prevalence of homocysteine-related diseases may be related to cystathionine $\beta$-synthase deficiency. However, cystathionine $\beta$-synthase deficiency in homozygous form, which can cause extreme elevations in homocysteine levels, is rare with a worldwide birth prevalence of 1:300 000. Moreover, although heterozygosity for cystathionine $\beta$-synthase deficiency, a mutation at a low prevalence $(<1 \%)$, may cause an elevated

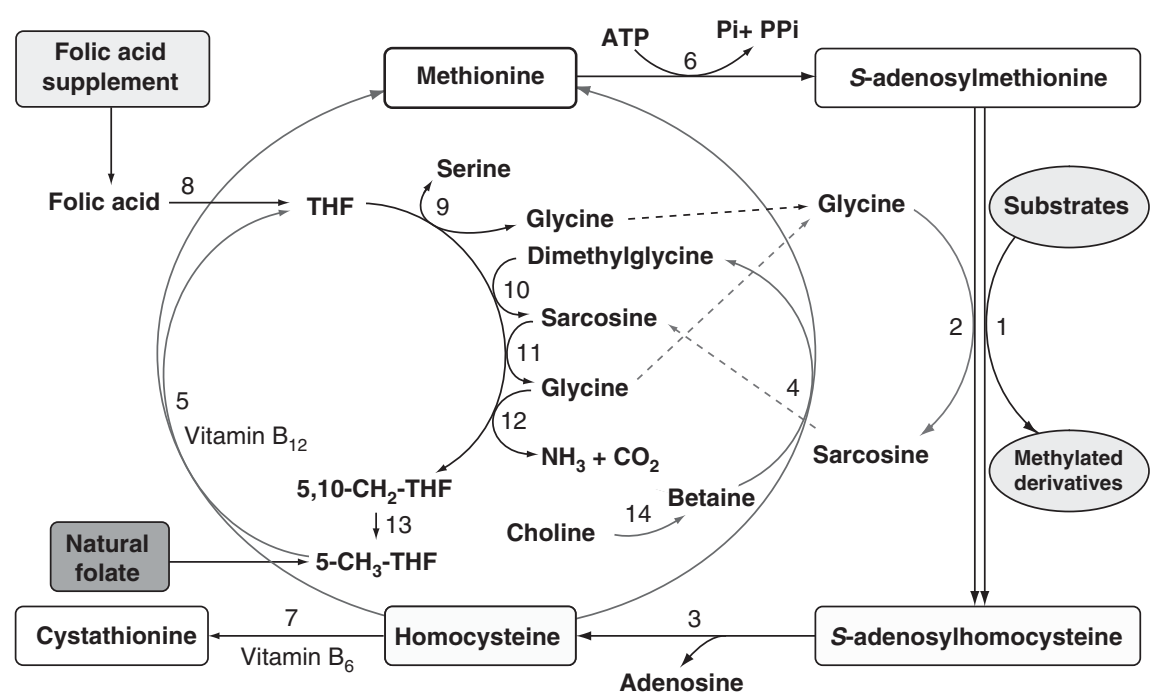

Figure 1 The methionine-homocysteine cycle and methylation of exogenous/endogenous substrates. The role of methionine-homocysteine cycle is to generate universal methyl donor S-adenosylmethionine for methylating a variety of exogenous/endogenous substrates. Homocysteine, produced in the methylation reaction, can be remethylated to methionine by a folate-dependent pathway or a betaine-dependent pathway. Adequate supply of methyl donors, especially betaine and choline, is needed to maintain the methionine-homocysteine cycle. Unlike natural folate, synthetic folic acid has to be converted to 5-methyltetrahydrofolate before it can function, which is a methyl-consuming reaction. (1) Various S-adenosylmethionine-dependent methyltransferases; (2) glycine $\mathrm{N}$-methyltransferase; (3) adenosylhomocysteinase; (4) betaine-homocysteine S-methyltransferase; (5) methionine synthase; (6) methionine adenosyltransferase; (7) cystathionine $\beta$-synthase; (8) dihydrofolate reductase; (9) glycine hydroxymethyltransferase; (10) dimethylglycine dehydrogenase; (11) sarcosine dehydrogenase; (12) glycine cleavage system; (13) methylenetetrahydrofolate reductase; (14) choline oxidase. THF, tetrahydrofolate. A full color version of this figure is available at the Hypertension Research journal online. 
postmethionine loading plasma homocysteine, this mutation has little effect on the fasting homocysteine levels. ${ }^{26}$ Supplementation of vitamin $\mathrm{B}_{6}$, an essential cofactor for cystathionine $\beta$-synthase, also has no effect on cardiovascular events. ${ }^{25}$ Therefore, the frequency of carriers of cystathionine $\beta$-synthase deficiency alone cannot explain the high incidence of hyperhomocysteinemia, neither in healthy nor in vascular populations. ${ }^{26}$

One unexplored cause for the increasing prevalence of metabolic syndrome, T2D and CVD are changes in dietary content of methyl consumers. It is known that almost all of the homocysteine is derived as an intermediate in the methionine-homocysteine cycle, because the amount of homocysteine from dietary sources is very limited. ${ }^{27}$ This means that the methylation of both endogenous and exogenous methyl consumers provides the dominant source of plasma homocysteine. Although guanidinoacetate and phosphatidylethanolamine are known to be two major endogenous methyl consumers used to synthesize creatine and phosphatidylcholine, respectively, ${ }^{28}$ there is no evidence of increase in the level of guanidinoacetate or phosphatidylethanolamine in metabolic syndrome or its related diseases. In contrast, increased exogenous methyl consumers, such as niacin, ${ }^{26,29,30}$ levodopa ${ }^{31}$ and arsenic, ${ }^{32}$ may contribute to elevated plasma homocysteine levels. Given that diet is a major risk factor for hyperhomocysteinemia ${ }^{33}$ and that there has been a significant increase in dietary methyl consumers in the past few decades due to pollution, food additives, food fortification and high meat intake, ${ }^{34,35}$ it seems very likely that increased dietary methyl consumers may be a significant factor in the prevalence of hyperhomocysteinemia and its related diseases.

Some studies indicated that hyperhomocysteinemia is rarely seen in metabolic syndrome, ${ }^{36,37}$ but frequently seen in its primary clinical outcomes, T2D ${ }^{9-11}$ and CVD. ${ }^{8,12}$ This phenomenon may reflect a difference in the compensatory capacity in the conversion of homocysteine to methionine or cystathionine, since plasma homocysteine levels are also found to go up with age. ${ }^{9,38,39}$ Moreover, because the production of homocysteine is mainly determined by diet, ${ }^{33}$ metabolic syndrome patients, even those with CVD, may have normal plasma homocysteine if they have shifted to a low methyl consumer diet and/ or have a higher capability to convert homocysteine to methionine (for example, due to folate supplementation) or to cystathionine. From this point of view, it seems that plasma homocysteine may not be a reliable indicator of the imbalance between methyl supply and consumption, especially in the early stage of metabolic syndrome.

\section{METHYL CONSUMERS AND THE METABOLIC SYNDROME}

To date, although few studies have attempted to explain the etiology and prevalence of metabolic syndrome from the standpoint of increased methyl consumers, numerous studies have provided strong evidence that methyl consumers, both endogenous and exogenous, may be involved in the pathogenesis of metabolic syndrome and its related diseases. To outline the relationship between increased methyl consumers and the increased prevalence of metabolic syndrome and its related diseases, common examples are given below.

\section{Arsenic}

Arsenic is a ubiquitous environmental contaminant and is also one of the most common methyl consumers. In the human body, inorganic pentavalent arsenic is converted to trivalent arsenic, with subsequent methylation to monomethylarsonic acid, then to dimethylarsinic acid, and finally to trimethylarsine oxide, ${ }^{40}$ which indicates that one inorganic arsenic may consume three methyl groups derived from SAM. Therefore, arsenic exposure may lead to a depletion of the SAM pool.
The human health effects of arsenic have been extensively studied. Chronic exposure to arsenic has been recognized to cause various types of human diseases, including metabolic syndrome, T2D, CVD and various cancers, ${ }^{40-44}$ which may contribute to the prevalence of metabolic syndrome in arsenic-polluted areas. The mechanism underlying arsenic toxicity is believed to be due to methyl depletion-induced aberrant DNA methylation, and excessive ROS generation and subsequent oxidative cell injury. ${ }^{40-42,45}$

\section{Niacin}

Niacin (nicotinic acid and nicotinamide) is a water-soluble vitamin and a common methyl consumer. ${ }^{46}$ Dietary nicotinic acid is derived from plant foods, while nicotinamide is derived from animal foods and typically used for food fortification. Fortified grains have provided an additional niacin source. Excessive niacin is converted to $N^{1}$-methylnicotinamide via an SAM-dependent methylation, and then to pyridinones. ${ }^{46}$ This metabolic pathway depends on the supply of SAM and methyl donors. However, there is some difference between the degradation of the two active forms of niacin. Nicotinic acid can be either converted to nicotinamide and then degraded via the nicotinamide catabolic pathway (methyl-consuming catabolic pathway), or excreted in the urine unchanged and as nicotinuric acid (non-methyl-consuming catabolic pathway). ${ }^{47}$ In contrast, nicotinamide is rarely excreted into the urine in its original form due to a high rate of tubular reabsorption. ${ }^{48}$ Thus, equivalent doses of nicotinamide may consume more methyl groups than nicotinic acid.

The well-known toxicities of niacin are glucose intolerance, insulin resistance, liver enzyme elevations, fatty liver and steatosis. ${ }^{46,49-55}$ Our recent studies have shown that there is a strong lag-correlation between the prevalence of obesity and diabetes in the US population and the increased per capita consumption of niacin, which was attributed primarily to the consumption of fortified grains. ${ }^{34,35}$

The toxic effects of niacin may involve a variety of mechanisms, including methyl depletion, changes in NAD-dependent reactions and excessive ROS generation. Methyl depletion as a consequence of niacin toxicity has been confirmed by the observations that hepatic toxicity can be prevented by choline and betaine supplements. ${ }^{30,55}$ It is known that methyl deficiency may limit the formation of very low density lipoprotein and low density lipoprotein in the liver due to decreased phosphatidylcholine synthesis, which may result in a decrease in the levels of plasma very low density lipoprotein and low density lipoprotein, as demonstrated in rats by Mookerjea et al. ${ }^{56}$ On the other hand, the decreased transport of fat from the liver may lead to an accumulation of fat in the liver, and as a result, fatty liver and steatosis may occur. ${ }^{57}$ Moreover, adequate phosphatidylcholine is also required for the formation and clearance of chylomicrons from the intestinal mucosa. ${ }^{58}$ Therefore, methyl deficiency-induced decrease in phosphatidylcholine synthesis is also expected to reduce the plasma chylomicron levels. Similarly, choline deficiency has been demonstrated to lower the level of plasma chylomicrons. ${ }^{56}$ Interestingly, niacin has been found to induce both lipid-lowering effect ${ }^{52}$ and adverse hepatic outcomes. ${ }^{46,52,54,55}$ Thus, it seems that the lipidlowering effect of niacin may be mediated by methyl depletion, which, although improving cardiovascular outcomes, may increase the risk of adverse hepatic outcomes.

Niacin is the precursor of the important coenzymes NAD and NADP. NAD levels are dramatically altered by dietary levels of niacin. ${ }^{59}$ Since NAD and NADP are crucial in redox reactions, ${ }^{59}$ excessive niacin may lead to significant impacts on the redox status of the body by affecting NAD contents. Our recent study demonstrated that excessive nicotinamide might increase the generation of 
hydrogen peroxide, a highly ROS, and have a role in the development of insulin resistance. ${ }^{35,60}$

It is interesting to know whether niacin fortification may have adverse effects. Although niacin fortification has been implemented to prevent niacin deficiency (that is, pellagra) for more than half a century, there are virtually no studies that document and track the long-term changes of the levels of plasma niacin and labile methyl donors, or the changes in the redox status. The fact that there is no prevalence of niacin deficiency (that is, pellagra) occurring in nonniacin-fortified developed countries in the past half century suggests that the risk for developing niacin deficiency may be overestimated and that niacin fortification may be redundant. In the absence of niacin deficiency, fortification-induced long-term high-level niacin exposure may lead to persistent niacin overload. It has shown that nicotinamide at physiological concentrations is degraded mainly via the methyl-consuming mechanism, ${ }^{61}$ and that the appearance of nonmethylated metabolites of nicotinamide in urine indicates nicotinamide overload and toxicity. ${ }^{47,62}$ Most importantly, long-term highlevel niacin exposure has been observed to induce a methyl-group deficiency state and fatty liver due to an increased need for methylation of niacin in animal studies. ${ }^{55,63}$

Based on current evidence, it seems likely that increases in niacin consumption may be correlated to the following phenomena: (1) the prevalence of T2D in the United States has increased in parallel with the increase in per capita consumption of niacin-fortified grains since the implementation of niacin fortification, whereas traditional high intake of non-fortified grain is associated with very low rates of obesity and diabetes; ${ }^{34}$ (2) the prevalence of metabolic syndrome-related diseases in niacin-fortified countries is much higher than that of non-fortified developed countries; ${ }^{34}$ (3) high consumption of meat, a nicotinamide-rich food, may increase the risk for metabolic syndrome; ${ }^{64}$ and (4) consumption of processed meat, in which niacin is used in meat coloring in some non-European countries, can significantly increase the risk of T2D. ${ }^{65}$

\section{Catecholamines}

Catecholamines, primarily norepinephrine and epinephrine that mediate the cardiovascular effect of the sympathetic system, ${ }^{66}$ are important endogenous methyl consumers. Catecholamines are known to be a major risk factor for hypertension and CVD, because they can increase heart rate, blood pressure and ROS production. ${ }^{67-70}$

Elevated catecholamines may be caused by two factors: (1) an increase in catecholamines release from the sympathetic nervous system and (2) a decrease in their degradation (that is, inactivation). Methylation is a crucial step in the degradation of catecholamines, which involves two methyltransferases: phenylethanolamine $\mathrm{N}$-methyltransferase and catechol $O$-methyltransferase, where the former catalyzes norepinephrine to epinephrine and the latter converts catecholamines to methylated derivatives. ${ }^{66}$ A lack of methyl groups may decrease the degradation of catecholamines and thus contribute to elevated circulating catecholamines. Hence, the increased level of unmethylated intermediates of catecholamines, such as dihydroxyphenylglycol and dihydroxymandelic acid ${ }^{71-73}$ observed in patients with hypertension and CVD may be related to methyl depletion/deficiency.

Since the methylation reactions of both catecholamines and exogenous methyl consumers utilize SAM as a methyl donor, it is expected that the decrease in the levels of SAM and methyl donors as induced by excessive exogenous methyl consumers may limit the methylation-mediated degradation of catecholamines. In this regard, we have recently observed that in healthy subjects, an excess of niacin can significantly increase the levels of plasma norepinephrine and homocysteine and was associated with a significant decrease in the levels of plasma betaine and normetanephrine as the methylated derivative (unpublished data), which suggests that chronic high niacin intake may contribute to elevated circulating catecholamines.

\section{Folic acid}

Folic acid, the synthetic oxidized form of folate used for supplementation and fortification, is an unusual methyl consumer. Unlike 5-methyltetrahydrofolate which is the predominant natural form of folate in plants, ${ }^{74}$ folic acid has to be reduced to tetrahydrofolate, and then further converted to the active form 5-methyltetrahydrofolate in the body (Figure 1). As shown in Figure 1, the formation of 5,10methylenetetrahydrofolate from tetrahydrofolate requires a onecarbon unit from serine, dimethylglycine, sarcosine or glycine. The latter three compounds may be derived from betaine or its precursor choline. Also, the one-carbon unit for the formation may be derived from SAM through the glycine-sarcosine cycle (Figure 1), which is an important factor in determining the level of SAM. ${ }^{20}$ Evidently, the formation of 5-methyltetrahydrofolate from folic acid is a process also dependent on SAM and other methyl donors.

Most importantly, excessive folic acid is eliminated through the urine primarily in its metabolic forms, ${ }^{20}$ especially 5 -methyltetrahydrofolate ${ }^{75}$ and thus results in a waste of SAM and the methyl donors. Folic acid supplementation and fortification have been found to significantly increase the urinary excretion of 5-methyltetrahydrofolate. $^{75}$ Theoretically, excessive folic acid may worsen rather than alleviate methyl-group deficiency. In fact, studies have demonstrated that folic acid supplementation neither lowers SAH, nor increases SAM, nor alters SAM/SAH ratio. ${ }^{76}$ This may explain why folic acid supplementation has generally failed to reduce vascular events in clinical trials, ${ }^{22-25}$ or even has potential harmful effect on individuals with high homocysteine at baseline. ${ }^{24}$ It should be pointed out that in most case, the reverse association between low vegetable intake and metabolic syndrome-related diseases is attributed to folate deficiency. ${ }^{20}$ Vegetables generally contain much more betaine than folate. For example, $100 \mathrm{~g}$ of spinach, one of the richest vegetable sources of folate, contains only $\sim 50 \mu \mathrm{g}$ of folate, ${ }^{74}$ but has $\sim 600 \mathrm{mg}$ of betaine and $22 \mathrm{mg}$ of choline. ${ }^{77}$ Therefore, diet-induced folate deficiency may be accompanied by a more severe deficiency of methyl-group donors. Thus, it seems that the importance of folate in the increasing prevalence of metabolic syndrome and its related diseases is overestimated.

Taken together, the dramatic worldwide increase in the intake of methyl-consuming compounds due to pollution and fortification might be responsible for the increasing prevalence of metabolic syndrome and its related diseases. The amount of methyl consumers from dietary sources may vary depending on the degree of pollution, implementation of food fortification and fortification standards. All of these differences may account for the difference in the prevalence of metabolic syndrome among countries or regions.

\section{PROPOSED MECHANISM FOR THE EFFECTS OF METHYL CONSUMERS}

Figure 2 shows the mechanism we proposed to explain the relationship between increased methyl consumers and metabolic syndrome. Methyl consumers may cause metabolic syndrome and its related diseases by a combination of oxidative stress and methyl-group depletion.

The metabolism of methyl consumers generates ROS that may lead to systemic oxidative stress, which is a key pathogenic factor in the development of T2D and CVD. Thus, chronic exposure to excessive 


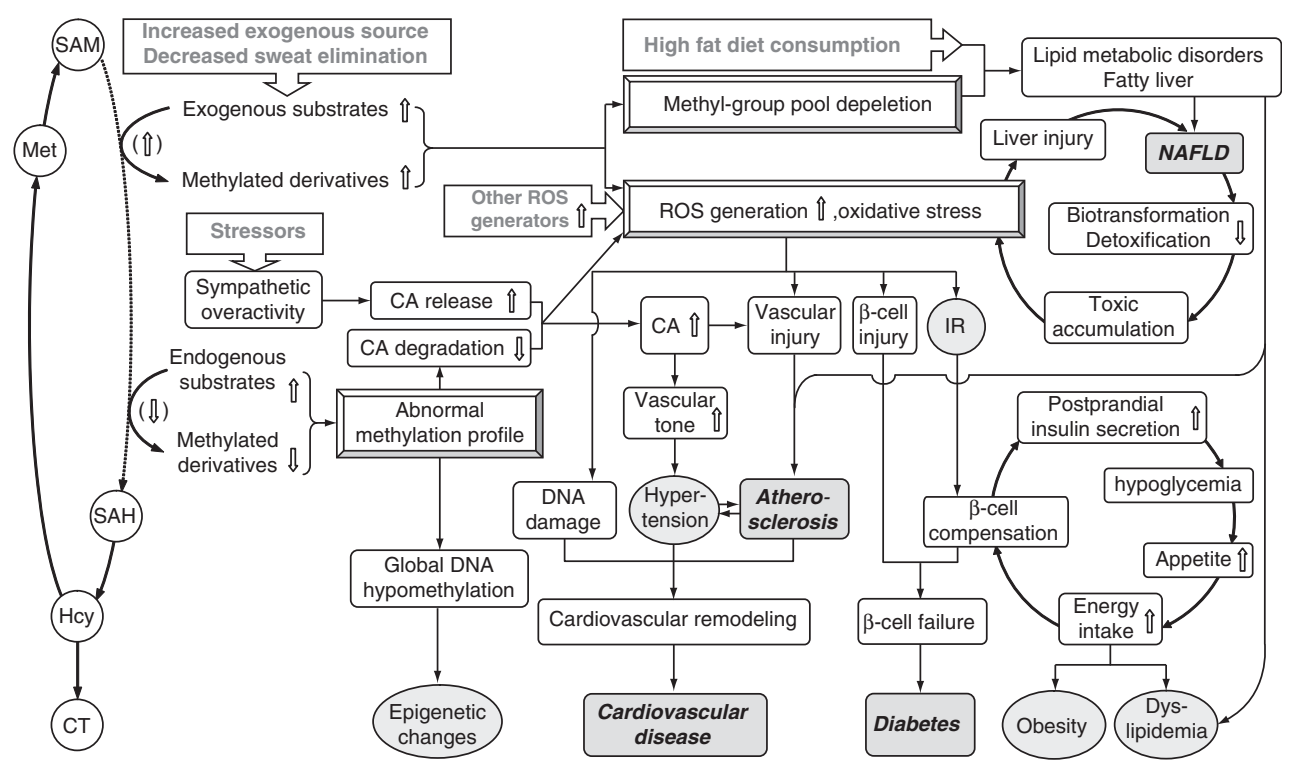

Figure 2 Proposed methyl consumer poisoning hypothesis for the pathogenesis of metabolic syndrome. The pathogenesis of metabolic syndrome may involve a combination of factors, in which exogenous methyl consumer-induced methyl depletion and oxidative stress are the primary cause. Factors, including other xenobiotics, high fat intake, decrease skin functions (especially sweat elimination) and stressors, are the secondary causes. All of the components and the primary clinical outcomes of the metabolic syndrome result from oxidative injury and methyl depletion/deficiency (see text for more detail). Met, methionine; SAM, S-adenosylmethionine; SAH, S-adenosylhomocysteine; Hcy, homocysteine; CT, cystathionine. ROS, reactive oxygen species; $\mathrm{CA}$, catecholamines; IR, insulin resistance; NAFLD, non-alcoholic fatty liver disease. Up hollow arrow indicates increase and down hollow arrow indicates decrease. A full color version of this figure is available at the Hypertension Research journal online.

methyl consumers may result in extensive oxidative injury, including liver, vascular and islet $\beta$-cell injury, as well as insulin resistance, which are observed in metabolic syndrome and its related diseases. Most importantly, liver injury may delay the clearance of toxic substances and further promote the development of metabolic syndrome. This may explain the observed association between liver diseases and metabolic syndrome. ${ }^{78}$

The property of dietary methyl consumer-induced oxidative stress is that it occurs soon after meal due to excessive ROS generation, which leads to an increase in early postprandial insulin secretion due to $\beta$-cell compensation, and then is gradually attenuated with the clearance of the produced ROS. However, the clearance of plasma insulin is slower than that of the produced ROS, so increased plasma insulin may induce late postprandial hypoglycemia with the recovery of insulin sensitivity, and thus increase appetite. Such a change has been observed by using an oral glucose tolerance test plus nicotinamide in young healthy subjects. ${ }^{35}$ The increased appetite may lead to an increase in energy intake and subsequent obesity. As a result, the long-term persistent $\beta$-cell compensation together with the oxidative $\beta$-cell damage may eventually induce $\beta$-cell failure and T2D, which may account for the associations between $\operatorname{arsenic}^{42-44}$ or niacin ${ }^{34,35}$ exposure and the prevalence of metabolic syndrome and its related diseases.

On the other hand, increased methyl consumer-induced methyl depletion may upset the balance between methyl-group supply and consumption, and thus disturb all the methylation reactions of the body, including phosphatidylcholine synthesis, catecholamine degradation and DNA methylation. Decreased phosphatidylcholine synthesis limits the syntheses of lipoproteins, which would lead to accumulation of fat and cholesterol in the liver and subsequent fatty liver and lipid profile changes. The combination of methyl consumerinduced liver injury and fatty liver may have a role in the development of non-alcoholic fatty liver disease, a common disease in the Western world. Decreased methylation-mediated catecholamine inactivation may lead to an increase in circulating catecholamines, which contributes to the development of oxidative stress, hypertension and atherosclerosis. Excessive methyl consumer-induced methyl depletion may affect DNA methylation status, as observed in arsenic exposure. ${ }^{45}$

Moreover, some secondary factors may contribute substantially to the development of the disease. These factors include: (1) other ROS-generating xenobiotics or compounds, such as alcohol, (2) chronic mental stress and (3) lifestyle-related factors such as high fat intake, low vegetable intake and decreased skin functions (primarily sweat elimination) (Figure 1). The other ROS-generating xenobiotics may worsen oxidative stress and liver injury, and thus promote the development of metabolic syndrome. Mental stress such as depression, anxiety and hyperactivity is linked to an increased sympathetic overactivity ${ }^{79}$ which may induce more catecholamines release and thus accelerate cardiovascular outcomes. High fat intake is a major causal factor in lipid disorders, and low vegetable intake decreases the supply of betaine, a major methyl donor; hence, the combination of high fat intake and methyl depletion/deficiency may accelerate the development of fatty liver and atherosclerosis.

Decreased skin functions might be a potent risk factor for metabolic syndrome and its related diseases, which has not yet received much attention. Skin being the largest organ in the body has two major functions linked to the clearance of xenobiotics. They involve the xenobiotic-metabolizing enzymes ${ }^{80}$ and the sweat glands. ${ }^{81}$ Most importantly, some toxic compounds (for example, nicotinamide ${ }^{60}$ ) cannot be effectively excreted through urine in its natural form, but can be eliminated through sweat. Therefore, sweating can prevent oxidative stress and also avoid methyl depletion. Evidently, skin functions are no doubt influenced by skin integrity and the body surface temperature. Decreased skin functions by low ambient temperature (for example, cold season), physical inactivity (especially sedentary in air-conditioned environments) or skin loss (for example, severe burn) may increase the risk for metabolic syndrome and its 
outcomes. The changes in skin functions may, at least in part, underlie the following phenomena: (1) sweating exercise can reduce the incidence of diabetes, ${ }^{82}$ whereas sedentary lifestyles may increase the risk for metabolic syndrome; ${ }^{83}$ (2) there is a high incidence of hyperhomocysteinemia in athletes of winter sports, ${ }^{84}$ and the symptoms of T2D and CVD are worse in winter; ${ }^{85,86}$ (3) severe burn is frequently associated with persistent insulin resistance; 87 and (4) extensive skin diseases such as psoriasis are frequently associated with metabolic diseases including metabolic syndrome, diabetes and non-alcoholic fatty liver disease. ${ }^{88}$

Figure 2 shows that the toxicity of methyl consumers is not merely a matter of methyl depletion. Supplementation of methyl donors, although alleviating methyl consumer-induced methyl depletion, cannot prevent methyl consumer-induced ROS generation and the resultant oxidative cell damage. This implies that without reducing the level of methyl consumers, supplementation of methyl donors alone may not achieve the desired therapeutic effect.

\section{CONCLUSIONS}

The pathogenesis of metabolic syndrome may involve an imbalance of methyl supply consumption. In the past few decades, in addition to a significant increase in exogenous methyl-consuming compounds, especially from dietary sources due to pollution, food fortification and high meat consumption, there is also a significant decrease in the elimination/metabolism of xenobiotics, especially due to the decrease in skin function as influenced by lifestyle changes. These may be major causes of the increased prevalence of metabolic syndrome and its related diseases worldwide. Therefore, it seems that decreasing dietary methyl-consuming compounds (for example, using natural foods rather than fortified or additive-containing foods) may be a key factor in the prevention and treatment of metabolic syndrome, T2D and CVD.

\section{CONFLICT OF INTEREST}

The authors declare no conflict of interest.

\section{ACKNOWLEDGEMENTS}

This work was supported by National Natural Science Foundation of China (No. 30570665), the Foundation of Key Laboratory of Education Department of Liaoning Province (No. 2009S005) and the Foundation of Dalian Technology Bureau (No. 2008E13SF182).

1 Roberts CK, Sindhu KK. Oxidative stress and metabolic syndrome. Life Sci 2009; 84: 705-712.

2 Gallou-Kabani C, Junien C. Nutritional epigenomics of metabolic syndrome: new perspective against the epidemic. Diabetes 2005; 54: 1899-1906.

3 Flegal KM, Carroll MD, Ogden CL, Johnson CL. Prevalence and trends in obesity among US adults, 1999-2000. JAMA 2002; 288: 1723-1727.

4 The US Centers for Disease Control and Prevention's National Center for Health Statistics Prevalence of Obesity Among Children and Adolescents: United States, Trends 1963-1965 Through 2007-2008 http://www.cdc.gov/nchs/data/hestat/obesity child_07_08/obesity_child_07_08.htm.Last accessed on 19 April 2011.

5 The US Centers for Disease Control and Prevention's National Center for Health Statistics Crude and Age-Adjusted Percentage of Civilian, Noninstitutionalized Population with Diagnosed Diabetes, United States, 1980-2008 http://www.cdc.gov/diabetes/ statistics/prev/national/figage.htm. Last accessed on 19 April 2011.

6 Andreassi MG. Metabolic syndrome, diabetes and atherosclerosis: influence of geneenvironment interaction. Mutat Res 2009; 667: 35-43.

7 Konstantinova SV, Tell GS, Vollset SE, Nygård O, Bleie $\varnothing$, Ueland PM. Divergent associations of plasma choline and betaine with components of metabolic syndrome in middle age and elderly men and women. J Nutr 2008; 138: 914-920.

8 McCully KS. Homocysteine and vascular disease. Nat Med 1996; 2: 386-389.

9 Dominguez LJ, Galioto A, Pineo A, Ferlisi A, Ciaccio M, Putignano E, Belvedere M, Costanza G, Barbagallo M. Age, homocysteine, and oxidative stress: relation to hypertension and type 2 diabetes mellitus. J Am Coll Nutr 2010; 29: 1-6.
10 González R, Pedro T, Real JT, Martínez-Hervás S, Abellán MR, Lorente R, Priego A, Catalá M, Chaves FJ, Ascaso JF, Carmena R. Plasma homocysteine levels are associated with ulceration of the foot in patients with type 2 diabetes mellitus. Diabetes Metab Res Rev 2010; 26: 115-120.

11 Becker A, Smulders YM, van Guldener C, Stehouwer CD. Epidemiology of homocysteine as a risk factor in diabetes. Metab Syndr Relat Disord 2003; 1: 105-120.

12 Hsieh MJ, Chen CC, Lee TH, Lee CH, Wen MS, Lin FC, Hsieh IC, Wu D. Metabolic syndrome and homocysteine level as predictors of the severity of coronary artery disease in patients with carotid stenosis. Am J Med Sci 2009; 338: 447-452.

13 Yang BT, Dayeh TA, Kirkpatrick CL, Taneera J, Kumar R, Groop L, Wollheim CB, Nitert $M D$, Ling C. Insulin promoter DNA methylation correlates negatively with insulin gene expression and positively with $\mathrm{HbA}(1 \mathrm{c})$ levels in human pancreatic islets. Diabetologia 2011; 54: 360-367.

14 Sookoian S, Rosselli MS, Gemma C, Burgueño AL, Fernández Gianotti T, Castaño GO, Pirola CJ. Epigenetic regulation of insulin resistance in nonalcoholic fatty liver disease: impact of liver methylation of the peroxisome proliferator-activated receptor ã coactivator 1á promoter. Hepatology 2010; 52: 1992-2000.

15 Gemma C, Sookoian S, Dieuzeide G, García SI, Gianotti TF, González CD, Pirola CJ. Methylation of TFAM gene promoter in peripheral white blood cells is associated with insulin resistance in adolescents. Mol Genet Metab 2010; 100: 83-87.

16 Clarke S, Banfield K. S-Adenosylmethionine-dependent methyltransferases. In Carmel $\mathrm{R}$, Jacobsen DW (eds), Homocysteine in Health and Disease. Cambridge University Press: Cambridge, 2001, pp 63-78.

17 Craig SA. Betaine in human nutrition. Am J Clin Nutr 2004; 80: 539-549.

18 Ueland PM, Holm PI, Hustad S. Betaine: a key modulator of one-carbon metabolism and homocysteine status. Clin Chem Lab Med 2005; 43: 1069-1075.

19 Allen RH, Stabler SP, Savage DG, Lindenbaum J. Metabolic abnormalities in cobalamin (vitamin B12) and folate deficiency. FASEB J 1993; 7: 1344-1353.

20 Bailey LB, Moyers S, Gregory III JF. Folate. In Bowman BA, Russell RM (eds) Present Knowledge in Nutrition, 8th edn. International Life Sciences Institute Press: Washington, DC, 2001, pp 214-229.

21 Engbersen AM, Franken DG, Boers GH, Stevens EM, Trijbels FJ, Blom HJ. Thermolabile 5,10-methylenetetrahydrofolate reductase as a cause of mild hyperhomocysteinemia. Am J Hum Genet 1995; 56: 142-150.

22 Song Y, Cook NR, Albert CM, Van Denburgh M, Manson JE. Effect of homocysteinelowering treatment with folic Acid and B vitamins on risk of type 2 diabetes in women: a randomized, controlled trial. Diabetes 2009; 58: 1921-1928.

23 Ebbing M, Ueland PM. Prevention: B vitamins and CVD-failure to find a simple solution. Nat Rev Cardiol 2010; 7: 608-609.

24 Miller 3rd ER, Juraschek S, Pastor-Barriuso R, Bazzano LA, Appel LJ, Guallar E. Metaanalysis of folic acid supplementation trials on risk of cardiovascular disease and risk interaction with baseline homocysteine levels. Am J Cardiol 2010; 106: 517-527.

25 Lonn E, Yusuf S, Arnold MJ, Sheridan P, Pogue J, Micks M, McQueen MJ, Probstfield J, Fodor G, Held C, Genest Jr J. Homocysteine lowering with folic acid and B vitamins in vascular disease. N Engl J Med 2006; 354: 1567-1577.

26 Schneede J, Refsum H, Ueland PM. Biological and environmental determinants of plasma homocysteine. Semin Thromb Hemost 2000; 26: 263-279.

27 Jacobsen DW. Biochemistry and metabolism. In Robinson K (ed) Homocysteine and Vascular Disease. Kluwer: Dordrecht, 2000, pp 15-35.

28 Williams KT, Schalinske KL. Homocysteine metabolism and its relation to health and disease. Biofactors 2010; 36: 19-24.

29 Dierkes J, Westphal S. Effect of drugs on homocysteine concentrations. Semin Vasc Med 2005; 5: 124-139.

30 McCarty MF. Co-administration of equimolar doses of betaine may alleviate the hepatotoxic risk associated with niacin therapy. Med Hypotheses 2000; 55: 189-194.

31 Rogers JD, Sanchez-Saffon A, Frol AB, Diaz-Arrastia R. Elevated plasma homocysteine levels in patients treated with levodopa: association with vascular disease. Arch Neurol 2003; 60: 59-64.

32 Hall MN, Liu X, Slavkovich V, Ilievski V, Pilsner JR, Alam S, Factor-Litvak P, Graziano $\mathrm{JH}$, Gamble MV. Folate, cobalamin, cysteine, homocysteine, and arsenic metabolism among children in Bangladesh. Environ Health Perspect 2009; 117: 825-831.

33 Appel LJ, Miller 3rd ER, Jee SH, Stolzenberg-Solomon R, Lin PH, Erlinger T, Nadeau MR, Selhub J. Effect of dietary patterns on serum homocysteine: results of a randomized, controlled feeding study. Circulation 2000; 102: 852-857.

34 Zhou SS, Li D, Zhou YM, Sun WP, Liu QG. B-vitamin consumption and the prevalence of diabetes and obesity among the US adults: population based ecological study. BMC Public Health 2010; 10: 746 .

35 Li D, Sun WP, Zhou YM, Liu QG, Zhou SS, Luo N, Bian FN, Zhao ZG, Guo M. Chronic niacin overload may be involved in the increased prevalence of obesity in US children. World J Gastroenterol 2010; 16: 2378-2387.

36 Nabipour I, Ebrahimi A, Jafari SM, Vahdat K, Assadi M, Movahed A, Moradhaseli F, Obeidi N, Sanjdideh Z. The metabolic syndrome is not associated with homocysteinemia: the Persian Gulf Healthy Heart Study. J Endocrinol Invest 2009; 32: 406-410.

37 Budak N, Yazici C, Oztürk A, Bayram F, Mazicioalu MM, Kurtoglu S. Is plasma homocysteine level associated with metabolic syndrome components in adolescents? Metab Syndr Relat Disord 2009; 7: 357-362.

38 Strassburg A, Krems C, Lührmann PM, Hartmann B, Neuhäuser-Berthold M. Effect of age on plasma homocysteine concentrations in young and elderly subjects considering serum vitamin concentrations and different lifestyle factors. Int J Vitam Nutr Res 2004; 74: 129-136.

39 Powers RW, Majors AK, Lykins DL, Sims CJ, Lain KY, Roberts JM. Plasma homocysteine and malondialdehyde are correlated in an age- and gender-specific manner. Metabolism 2002; 51: 1433-1438. 
40 Hughes MF. Arsenic methylation, oxidative stress and cancer-is there a link? J Natl Cancer Inst 2009; 101: 1660-1661.

41 Druwe IL, Vaillancourt RR. Influence of arsenate and arsenite on signal transduction pathways: an update. Arch Toxicol 2010; 84: 585-596.

42 De Vizcaya-Ruiz A, Barbier O, Ruiz-Ramos R, Cebrian ME. Biomarkers of oxidative stress and damage in human populations exposed to arsenic. Mutat Res 2009; 674: 85-92.

43 Chen CJ, Wang SL, Chiou JM, Tseng CH, Chiou HY, Hsueh YM, Chen SY, Wu MM, Lai MS. Arsenic and diabetes and hypertension in human populations: a review. Toxicol Appl Pharmacol 2007; 222: 298-304.

44 Bhatnagar A. Environmental cardiology: studying mechanistic links between pollution and heart disease. Circ Res 2006; 99: 692-705.

45 Ren X, McHale CM, Skibola CF, Smith AH, Smith MT, Zhang L. An emerging role for epigenetic dysregulation in arsenic toxicity and carcinogenesis. Environ Health Perspect $2011 ; 119$ : 11-19.

46 Institute of Medicine. Dietary Reference Intakes for Thiamin, Riboflavin, Niacin, Vitamin B6, Folate, Vitamin B12, Pantothenic Acid, Biotin, and Choline. National Academy Press: Washington, DC, 1998, pp 123-149.

47 Menon RM, González MA, Adams MH, Tolbert DS, Leu JH, Cefali EA. Effect of the rate of niacin administration on the plasma and urine pharmacokinetics of niacin and its metabolites. J Clin Pharmacol 2007; 47: 681-688.

48 Knip M, Douek IF, Moore WP, Gillmor HA, McLean AE, Bingley PJ, Gale EA. Safety of high-dose nicotinamide: a review. Diabetologia 2000; 43: 1337-1345.

49 Chang AM, Smith MJ, Galecki AT, Bloem CJ, Halter JB. Impaired beta-cell function in human aging: response to nicotinic acid-induced insulin resistance. J Clin Endocrinol Metab 2006; 91: 3303-3309.

50 Greenbaum CJ, Kahn SE, Palmer JP. Nicotinamide's effects on glucose metabolism in subjects at risk for IDDM. Diabetes 1996; 45: 1631-1634.

51 Kahn SE, Beard JC, Schwartz MW, Ward WK, Ding HL, Bergman RN, Taborsky Jr GJ, Porte Jr D. Increased beta-cell secretory capacity as mechanism for islet adaptation to nicotinic acid-induced insulin resistance. Diabetes 1989; 38: 562-568.

52 Bays H. Safety of niacin and simvastatin combination therapy. Am J Cardiol 2008; 101: 3B-8B.

53 Ginsberg HN. Niacin in the metabolic syndrome: more risk than benefit? Nat Clin Pract Endocrinol Metab 2006; 2: 300-301.

54 Kristensen T, Olcott EW. Effects of niacin therapy that simulate neoplasia: hepatic steatosis with concurrent hepatic dysfunction. J Comput Assist Tomogr 1999; 23: 314-317.

55 Rikans LL, Arata D, Cederquist DC. Fatty livers produced in albino rats by excess niacin in high fat diets. II. Effect of choline supplements. J Nutr 1965; 85: 107-112.

56 Mookerjea S, Park CE, Kuksis A. Lipid profiles of plasma lipoproteins of fasted and fed normal and choline-deficient rats. Lipids 1975; 10: 374-382.

57 Garrow TA. Choline and carnitine. In Bowman BA, Russel RM (eds) Present Knowledge in Nutrition, 8th edn International Life Sciences Institute Press, Washington, DC, 2001, pp 261-272.

58 Mansbach II CM. The origin of chylomicron phosphatidylcholine in the rat. J Clin Invest 1977; 60: 411-420

59 Kirkland JB. Niacin status, NAD distribution and ADP-ribose metabolism. Curr Pharm Des 2009; 15: 3-11.

60 Zhou SS, Li D, Sun WP, Guo M, Lun YZ, Zhou YM, Xiao FC, Jing LX, Sun SX, Zhang LB, Luo N, Bian FN, Zou W, Dong LB, Zhao ZG, Li SF, Gong XJ, Yu ZG, Sun CB, Zheng CL, Jiang DJ, Li ZN. Nicotinamide overload may play a role in the development of type 2 diabetes. World J Gastroenterol 2009; 15: 5674-5684.

61 Hoshino J, Schlüter U, Kröger H. Nicotinamide methylation and its relation to NAD synthesis in rat liver tissue culture. Biochemical basis for the physiological activities of 1-methylnicotinamide. Biochim Biophys Acta 1984; 801: 250-258.

62 Shibata K, Shimada H, Taguchi H. Fate of nicotinamide differs due to an intake of nicotinamide. Biosci Biotechnol Biochem 1996; 60: 1204-1206.

63 Kang-Lee YA, McKee RW, Wright SM, Swendseid ME, Jenden DJ, Jope RS. Metabolic effects of nicotinamide administration in rats. J Nutr 1983; 113: 215-221.

64 Lutsey PL, Steffen LM, Stevens J. Dietary intake and the development of the metabolic syndrome: the Atherosclerosis Risk in Communities Study. Circulation 2008; 117: 754-761.
65 Fung TT, Schulze M, Manson JE, Willett WC, Hu FB. Dietary patterns, meat intake, and the risk of type 2 diabetes in women. Arch Intern Med 2004; 164: 2235-2240.

66 Kvetnansky R, Sabban EL, Palkovits M. Catecholaminergic systems in stress: structural and molecular genetic approaches. Physiol Rev 2009; 89: 535-606.

67 Goldstein DS. Plasma catecholamines and essential hypertension. An analytical review. Hypertension 1983; 5: 86-99.

68 Dhalla NS, Temsah RM, Netticadan T. Role of oxidative stress in cardiovascular diseases. J Hypertens 2000; 18: 655-673.

69 Behonick GS, Novak MJ, Nealley EW, Baskin SI. Toxicology update: the cardiotoxicity of the oxidative stress metabolites of catecholamines (aminochromes). J Appl Toxicol 2001; 21 (Suppl 1): S15-S22.

70 Marchitti SA, Deitrich RA, Vasiliou V. Neurotoxicity and metabolism of the catecholamine-derived 3,4-dihydroxyphenylacetaldehyde and 3,4-dihydroxyphenylglycolaldehyde: the role of aldehyde dehydrogenase. Pharmacol Rev 2007; 59: $125-150$.

71 Mizukoshi M, Hano T, Kuchii M, Nishio I, Masuyama Y. Plasma noradrenaline and its deaminated metabolites in essential hypertension and pheochromocytoma. Jpn Circ J 1985; 49: 1035-1042.

72 Ludwig J, Gerlich M, Halbrügge T, Graefe KH. Plasma norepinephrine and dihydroxyphenylglycol in essential hypertension. Hypertension 1991; 17: 546-552.

73 Ferrier C, Esler MD, Eisenhofer G, Wallin BG, Horne M, Cox HS, Lambert G, Jennings $\mathrm{GL}$. Increased norepinephrine spillover into the jugular veins in essential hypertension. Hypertension 1992; 19: 62-69.

74 Vahteristo L, Lehikoinen K, Ollilainen V, Varo P. Application of an HPLC assay for the determination of folate derivatives in some vegetables, fruits, and berries consumed in Finland. Food Chem 1997; 59: 589-597.

75 Caudill MA, Cruz AC, Gregory 3rd JF, Hutson AD, Bailey LB. Folate status response to controlled folate intake in pregnant women. J Nutr 1997; 127: 2363-2370.

76 Green TJ, Skeaff CM, McMahon JA, Venn BJ, Williams SM, Devlin AM, Innis SM. Homocysteine-lowering vitamins do not lower plasma S-adenosylhomocysteine in older people with elevated homocysteine concentrations. Br J Nutr 2010; 103: 1629-1634.

77 Zeisel SH, Mar MH, Howe JC, Holden JM. Concentrations of choline-containing compounds and betaine in common foods. J Nutr 2003; 133: 1302-1307.

78 Watanabe S, Yaginuma R, Ikejima K, Miyazaki A. Liver diseases and metabolic syndrome. J Gastroenterol 2008; 43: 509-518.

79 Black PH, Garbutt LD. Stress, inflammation and cardiovascular disease. J Psychosom Res 2002; 52: 1-23.

80 Svensson CK. Biotransformation of drugs in human skin. Drug Metab Dispos 2009; 37 : 247-253.

81 Sato K. The physiology, pharmacology, and biochemistry of the eccrine sweat gland. Rev Physiol Biochem Pharmacol 1977; 79: 51-131.

82 Manson JE, Nathan DM, Krolewski AS, Stampfer MJ, Willett WC, Hennekens CH. A prospective study of exercise and incidence of diabetes among US male physicians. JAMA 1992; 268: 63-67.

83 Ford ES, Li C, Zhao G, Pearson WS, Tsai J, Churilla JR. Sedentary behavior, physical activity, and concentrations of insulin among US adults. Metabolism 2010; 59 : 1268-1275.

84 Borrione P, Pigozzi F, Massazza G, Schonhuber H, Viberti G, Paccotti P, Angeli A. Hyperhomocysteinemia in winter elite athletes: a longitudinal study. J Endocrinol Invest 2007; 30: 367-375.

85 Reichert TA, Simonsen L, Sharma A, Pardo SA, Fedson DS, Miller MA. Influenza and the winter increase in mortality in the United States, 1959-1999. Am J Epidemiol 2004; 160: 492-502.

86 Keatinge WR, Donaldson GC. Cardiovascular mortality in winter. Arctic Med Res 1995; 54(Suppl 2): 16-18.

87 Gauglitz GG, Herndon DN, Kulp GA, Meyer 3rd WJ, Jeschke MG. Abnormal insulin sensitivity persists up to three years in pediatric patients post-burn. J Clin Endocrinol Metab 2009; 94: 1656-1664.

88 Gisondi P, Ferrazzi A, Girolomoni G. Metabolic comorbidities and psoriasis. Acta Dermatovenerol Croat 2010; 18: 297-304. 